\title{
Optimal PID tuning for controlling the temperature of electric furnace by genetic algorithm
}

\author{
Md. Manjurul Gani ${ }^{1} \cdot$ Md. Saiful Islam ${ }^{1} \cdot$ Muhammad Ahsan Ullah $^{1}$
}

(C) Springer Nature Switzerland AG 2019

\begin{abstract}
Temperature is one of the exigent parameters that needs to be controlled in today's industries. Importantly this temperature control should be precise and fast. As the conventional controllers are not optimally tuned, the controller used for controlling the temperature of the electric furnace does not exhibit better performance. Its rise time and settling time is too large as well as it has a sizable amount of overshoot. This paper presents a Genetic Algorithm based PID controller to overcome the low precision, long rise time and settling time of the controller. In this algorithm, Integral of Absolute Error is taken as the object function for minimizing the error. Using this function, the algorithm engenders the optimum value of the gain parameters $\left(\mathrm{K}_{\mathrm{p}}, \mathrm{K}_{\mathrm{i}}, \mathrm{K}_{\mathrm{d}}\right)$ for the PID controller. It shows better control over the conventional controllers. As the overshoot, settling time, and rise time are substantially improved, it provides sharp and prompt control over the temperature. This precise and instant control of temperature has a great impact on the food and medicine industries. As the temperature could be controlled precisely and instantly, we can avoid the change/degradation of the physical properties of the materials that are under process.
\end{abstract}

Keywords Precise · Optimum · PID · Genetic algorithm · Tune

\section{Introduction}

Electric furnace is one of the most commonly used furnaces in the industries. It converts the electric energy to mechanical energy (heat) for heating purpose. Temperature is an exigent parameter that requires control in the industries and in engineering [1]. If the temperature is not properly controlled, the physical properties of the processed material may change/degrade. So, it requires precise and fast control as far as possible.

There are manifold controlling methods in industries. Such as proportional-integral-derivative (PID) control, internal model control (IMC), predictive control, sliding mode control (SMC). But $90 \%$ of the industries use PID controller due to its simplicity, clear functionality and applicability [2].
Cohen-Coons as well as Ziegler-Nicholes (ZN) method is the most well known conventional PID tuning method [3]. Due to the non-linear characteristics of the system, tuning is a laborious task for the researchers. Besides system parameters may change with time. In these cases, an adaptive and intelligent controlling method could be a better option for it. Recently Bio-inspired intelligent computing methods (fuzzy logic (FIS), neural network (NN), genetic algorithm (GA)) are successfully applied to solve complex problems [4].

Traditional PID controllers are linear and require operators experience to adjust the coefficient, which is a timeconsuming process [5]. So, it requires the development of an optimum tuning method for the PID controller.

Genetic algorithm is an optimization (minimization) technique based on the evolution process. It was first proposed by Holland in 1975 [5] [6]. It is could be a powerful

Md. Saiful Islam, saiful05eee@gmail.com; Md. Manjurul Gani, gani.cuet@gmail.com; Muhammad Ahsan Ullah, ahsan_cuet@yahoo.com | ${ }^{1}$ Chittagong University of Engineering and Technology, Chittagong, Bangladesh.

SN Applied Sciences (2019) 1:880 | https://doi.org/10.1007/s42452-019-0929-y

Received: 21 December 2018 / Accepted: 16 July 2019 / Published online: 20 July 2019 
optimization tool for designing the controllers [3]. It can be used to optimize different error functions to obtain convenient PID parameters.

Vunlop and Wudhichai in [7] applied Nelder Mead method in search of the suitable value of PID using IAE as the cost function. And they show that their proposed method is more effective than Cohen-Coon method, ZN method, and Direct Synthesis method. In [8] Wei Jiang and Xuchu Jiang implement a Fuzzy tuned PID for a first order system (temperature controlling) and compared its response with the conventional PID controller. In paper [5] they apply the genetic algorithm based PID controller for a gas mixture system and found sharp and prompt control over the conventional PID controllers. The authors in paper [9] present a comparative study between GA PID controller and fuzzy self tuned PID controller for DC motor position controllers. In paper [10] they design a self learning fuzzy algorithm to optimize the PID controller parameters and found better performance. In [11] the authors design PID controller, GA based PID controller and GA based IMC controller to control the temperature of the heat exchanger and they found that GA based IMC controller shows better performance.

As the temperature is an important parameter in today's industries, it needs to be controlled precisely and quickly. This paper presents a Genetic Algorithm (GA) based PID controller to overcome the low precision, long rise time and settling time of the controller. The Genetic Algorithm (GA) is used to tune the PID controller. In this algorithm integral of absolute error (IAE) is considered as the object function. It shows better control over the conventional controllers. As the overshoot, settling time, and rise time are substantially improved, it provides sharp and prompt control over the temperature. This precise and instant control of temperature has a great impact on the food and medicine industries. As the temperature could be controlled precisely and instantly, we can avoid the change/ degradation of the physical properties of the materials that are under process.

The subsequent sections of this paper describe the following: PID controller, Genetic algorithms, temperature control system, proposed control approach and simulation result and analysis.

\section{Literature review}

\subsection{PID controller}

PID controller employs a fundamental control method with strong control property [12]. PID controllers are most commonly (around $90 \%$ of the controllers) adopted controller in the industries [13]. PID controller consists of three (03) basic gain parameters $\left(\mathrm{K}_{\mathrm{p}}, \mathrm{K}_{\mathrm{i}}, \mathrm{K}_{\mathrm{d}}\right)$ Schematic of PID controller is shown in Fig. 1. If the proportional gain rises, the rise time and the steady-state error decrease. If the $K_{i}$ increases, the rise time $\left(t_{r t}\right)$ decreases but the settling time $\left(t_{s t}\right)$ and the overshoot increase which can be overcome by the increase of the derivative gain. Here the input to the PID controller is e $(\mathrm{t})$ and output is $\mathrm{u}(\mathrm{t})$. The relation between the input and output is shown in Eq. 1 [14].

$u(t)=k_{p} e(t)+k_{i} \int e(t)+k_{d} \frac{d e(t)}{d t}$

Taking Laplace transformation:

$u(s)=k_{p} E(s)+k_{i} \frac{E(s)}{s}+s k_{d} E(s)$

$\frac{u(s)}{E(s)}=k_{p}+\frac{k_{i}}{s}+s k_{d}$

$C(s)=k_{p}+\frac{k_{i}}{s}+s k_{d}$

\subsection{Genetic algorithm}

Genetic Algorithms (GAs) are an optimization process that follows the process of natural evolution [15]. It is inspired by the process of selection and the mechanics of genetics [16]. These are a part of evolutionary computing i.e. artificial intelligence. The important part of GA is the selection of proper objective functions. We have to find out the optimum value of this function. Genetic algorithms search for the optimum solution and start blindly in search of best solution from a collection of a potential solution. These collections of the solutions are known as population and the each solution of the population is called chromosome. These chromosomes are compared among themselves based on their fitness value. Then the fittest member is selected. GA algorithm composed of 03 basic operations, mutation, crossover, and reproduction [17]. If this member does not meet the stopping criteria, the genetic

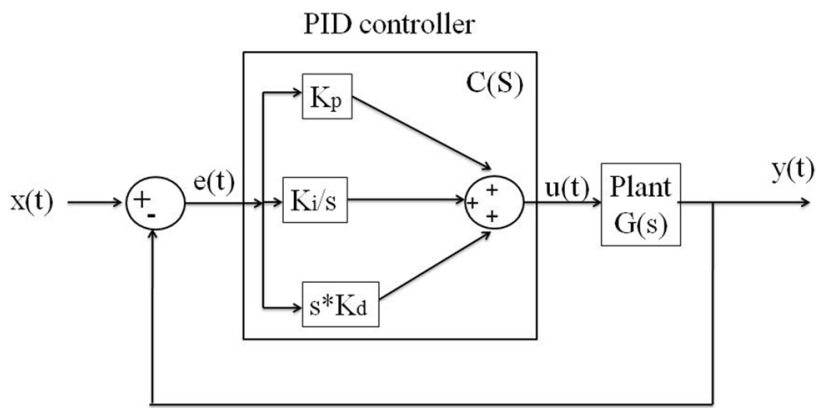

Fig. 1 PID controller 


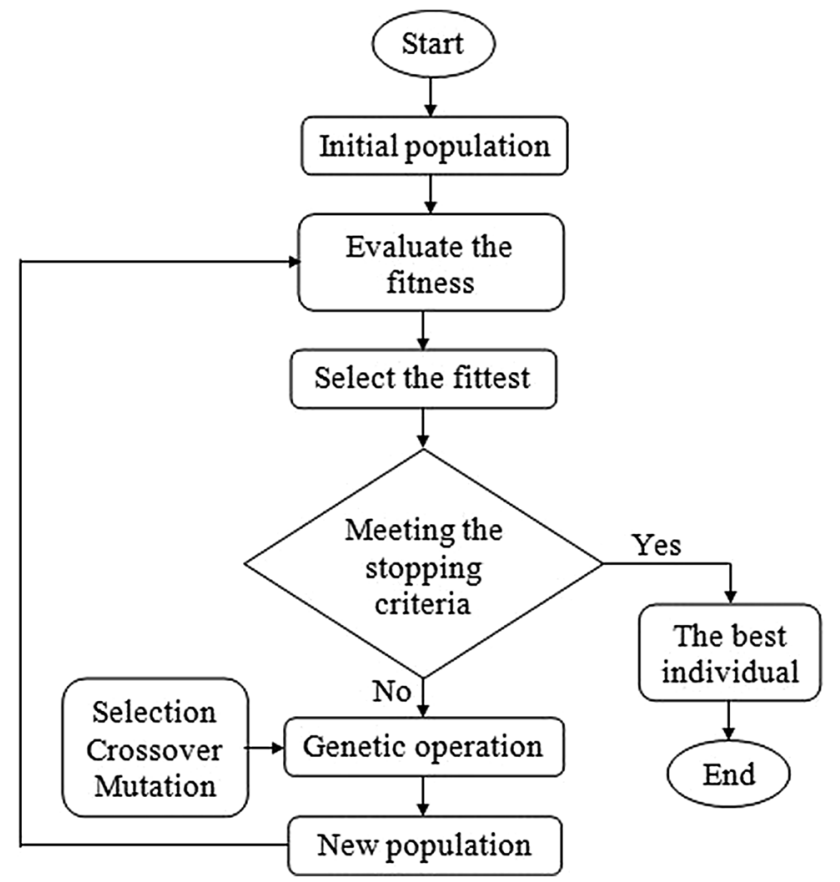

Fig. 2 Genetic Algorithm (GA)

algorithm applies its processes to create new population. This process goes on until the stopping criterion is met. The flow chart of the GA process is presented in Fig. 2 and it is described step by step below:

Step 01: Initial Population

The First step of the genetic algorithm is to declare the initial population which contains the possible solutions of the given problem.

Step 02: Evaluate the fitness

In this step, fitness of each individual is evaluated. The individuals i.e. the possible solutions are ranked based on the fitness value.

\section{Step 03: Genetic Operation}

The genetic operations follow the natural evaluation process. It includes three basic operations to create new population to find the optimum solution:

1. Selection In this operation, the individuals (chromosomes) are selected from the initial population for further processing. Now, the problem is how to select the chromosomes. According to Darwin's theory, the best individuals will survive and breeds new individuals (solutions). Generally, individuals with high fitness value are selected as the parent for crossover.

2. Crossover In crossover operation, it combines two selected parents to produce offspring (new solutions). It is a way of creating new solutions from the existing solutions. The crossover takes place according to a defined crossover probability.
3. Mutation After crossover, mutation takes place. Mutation means the flipping of the bits of the individuals i.e. flipping it 0 to 1 or 1 to 0 . In the mutation process, it flips the bits randomly based on small mutation probability.

Then again it goes to step 02 to evaluate the fitness. This process goes on until the stopping criteria are met.

\subsection{Temperature control system}

The electric furnace comprises of a furnace, controller, temperature, power regulator, sensor, heating coil etc. Here, the temperature is sensed by the sensor and produce a voltage, which is negative feedback to the input (set temperature). Based on the error voltage, the controller regulates the input power to the electric furnace.

The mathematical model of the above furnace can be described as [7]:

$$
G(s)=\frac{0.15}{s^{2}+1.1 s+0.2} e^{-1.5 s}
$$

Here the delay $e^{-1.5 s}$ is approximated as:

$e^{-1.5 s} \approx \frac{1-\frac{1.5}{2} s}{1+\frac{1.5}{2} s}=\frac{1-0.75 s}{1+0.75 s}$

Putting the value from Eq. (6) to Eq. (5) we get the overall system function is as follows.

$G(s)=\frac{-0.1125 s+0.15}{0.75 s^{3}+1.825 s^{2}+1.25 s+0.2}$

\section{Proposed temperature control approach}

Figure 3 shows the proposed GA based control method to tune the PID for the electric furnace. Here the plant $G(s)$ indicates the transfer function of the temperature control system of Fig. 4. The output temperature $y(t)$ is feedback to the input and compared with the set temperature $x(t)$. Thus the generated error signal $e(t)$ which

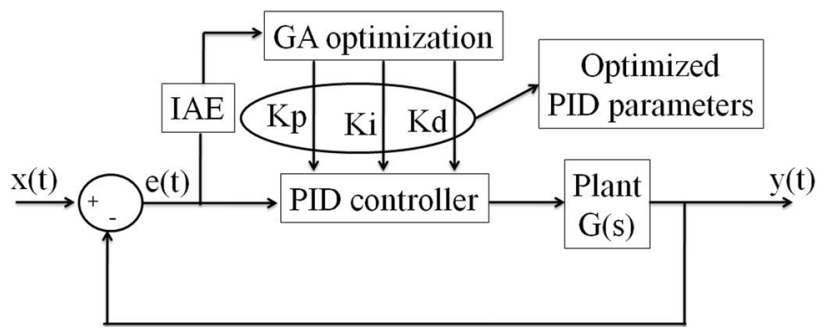

Fig. 3 Proposed GA based PID controller 


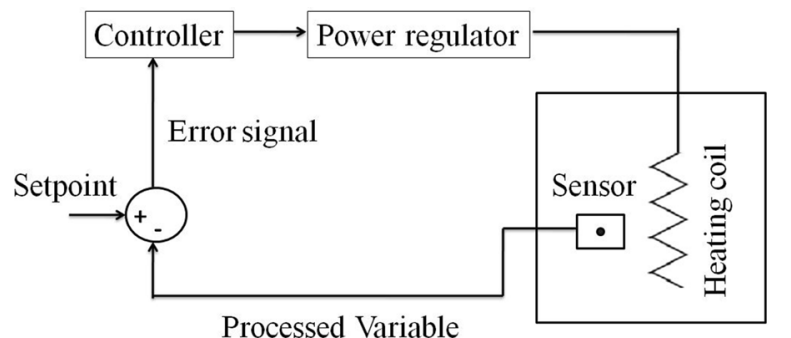

Fig. 4 Temperature control system

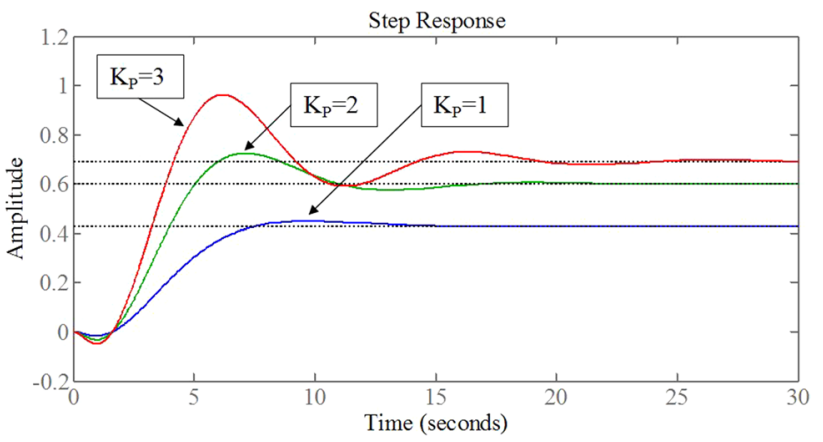

Fig. 5 Variation of characteristics parameters with the change of $\mathrm{K}_{\mathrm{p}}$

is the difference between the $x(t)$ and $y(t)$, governs the PID controller. The PID controller acts in such a way that it tries to minimize the error. On the other hand, the GA forms the object function (Integral of Absolute Error (IAE)) using the error signal to tune the PID controller. It is the function which is optimized by genetic algorithm. The proposed object function is mentioned in Eq. 8. The overall methodology is described step by step below:

Step 01: Selection of the gain parameters

The PID controller is used in cascade with the electric furnace. Here the three basic gain parameters of the PID type controller are $\mathrm{K}_{\mathrm{p}}, \mathrm{K}_{\mathrm{i}}$, and $\mathrm{K}_{\mathrm{d}}$. If $\mathrm{K}_{\mathrm{p}}$ rises, the rise time and the steady-state error decrease. Again, if $\mathrm{K}_{\mathrm{i}}$ increases, the rise time decreases but the overshoot and the settling time increase, which could be overcome by increasing the $\mathrm{K}_{\mathrm{d}}$. Following the Figs. 5, 6 and 7 and the Tables 1, 2 and 3 represents the variations of the characteristics parameters of the system with the change of gain parameters. From these tables it is apparent that the variations of the characteristics parameters are not uniform rather these are sometimes increasing, sometime decreasing, and sometimes fluctuating.

As the control characteristics (overshoot, rise time, and settling time) change with the variation of the gain parameters, one needs to choose the optimum value of the gain parameters $\left(K_{p}, K_{i}, K_{d}\right)$. So, the genetic algorithm

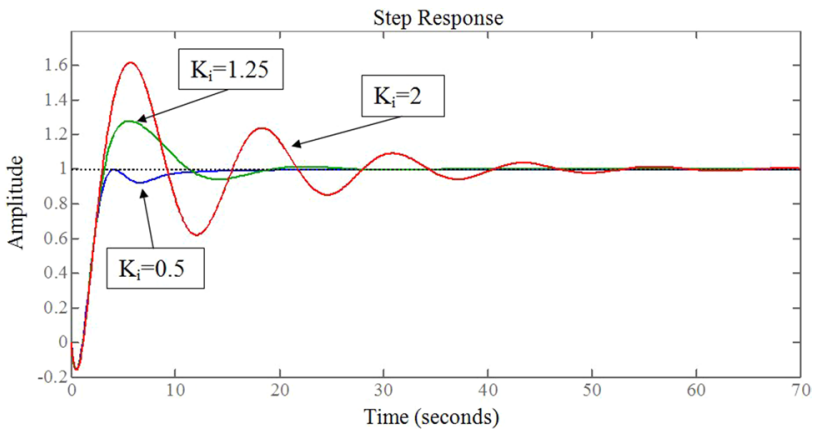

Fig. 6 Variation of characteristics parameters with the change of $\mathrm{K}_{\mathrm{i}}$

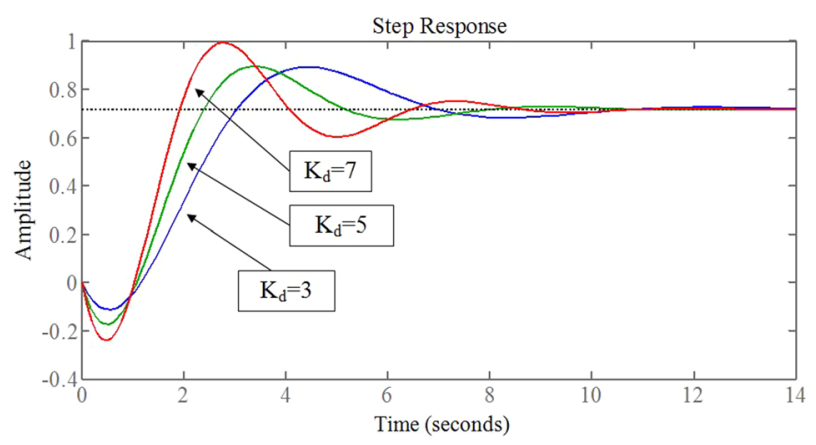

Fig. 7 Variation of characteristics parameters with the change of $K_{d}$

Table 1 Variation of characteristics parameters with the change of $\mathrm{K}_{\mathrm{p}}$

\begin{tabular}{llll}
\hline $\mathrm{K}_{\mathrm{p}}$ & Rise time (s) & Settling time (s) & $\begin{array}{l}\text { Percentage } \\
\text { overshoot } \\
(\%)\end{array}$ \\
\hline 1 & 4.04 & 12.7 & 4.69 \\
2 & 2.53 & 15.2 & 20.8 \\
3 & 1.90 & 18.4 & 38.9 \\
\hline
\end{tabular}

Table 2 Variation of characteristics parameters with the change of $\mathrm{K}_{\mathrm{i}}$

\begin{tabular}{llll}
\hline $\mathrm{K}_{\mathrm{i}}$ & Rise time (s) & Settling time (s) & $\begin{array}{l}\text { Percentage } \\
\text { overshoot } \\
(\%)\end{array}$ \\
\hline 0.5 & 1.79 & 10.2 & 0 \\
1.25 & 1.56 & 17.5 & 27.7 \\
2 & 1.43 & 45.2 & 61.6 \\
\hline
\end{tabular}

is applied to find the suitable (optimum) values of these gain parameters.

Step 02: Choosing the object function

The object function is an indispensable part of the genetic algorithm, which affects the functionality of the

\section{SN Applied Sciences}


Table 3 Variation of characteristics parameters with the change of $\mathrm{K}_{\mathrm{d}}$

\begin{tabular}{llll}
\hline $\mathrm{K}_{\mathrm{d}}$ & Rise time (s) & Settling time (s) & $\begin{array}{l}\text { Percentage } \\
\text { overshoot } \\
(\%)\end{array}$ \\
\hline 3 & 1.43 & 9.82 & 24.3 \\
5 & 1.01 & 7.38 & 24.6 \\
7 & 0.694 & 8 & 38.4 \\
\hline
\end{tabular}

Table 4 GA parameters

\begin{tabular}{ll}
\hline Parameters & Values \\
\hline Population type & Double vector \\
Fitness scaling (scaling function) & Rank \\
Creation function & Constraint dependent \\
Crossover & Single point \\
Selection & Roulette \\
Mutation & Uniform \\
Population size & 20 \\
\hline
\end{tabular}

Table 5 Range of $\mathrm{K}_{\mathrm{p}}, \mathrm{K}_{\mathrm{i}}$ and $\mathrm{K}_{\mathrm{d}}$

\begin{tabular}{lll}
\hline Parameters & $\begin{array}{l}\text { Mini- } \\
\text { mum } \\
\text { value }\end{array}$ & $\begin{array}{l}\text { Maxi- } \\
\text { mum } \\
\text { value }\end{array}$ \\
\hline $\mathrm{K}_{\mathrm{p}}$ & 1 & 4 \\
$\mathrm{~K}_{\mathrm{i}}$ & 0 & 2 \\
$\mathrm{~K}_{\mathrm{d}}$ & 3 & 7 \\
\hline
\end{tabular}

GA [5]. The genetic algorithm searches for the optimum (minimum) value of this object function. The genetic algorithm uses the error signal e(t), which is the difference between the set input and output to form the object function. It is the function which is optimized by genetic algorithm. Here the integral of absolute error (IAE) is considered as the object function for optimization which is mathematically represented by Eq. (8).

$I A E=\int_{0}^{\infty}|e(t)| d t$

\section{Step 03: Finding the optimum value using GA}

In this step genetic algorithm is applied to tune the PID controller i.e. to find the optimum value of $K_{d}, K_{i}$, and $K_{p}$. Parameters used for the genetic algorithm is given in Table 4. And Table 5 shows the rages of gain parameters that are used to find the optimum value of them. There is no specific rule for selecting the population size. Generally it is selected randomly. Here the population size and rages of gain parameters are determined based on trial and error for which the algorithm shows better

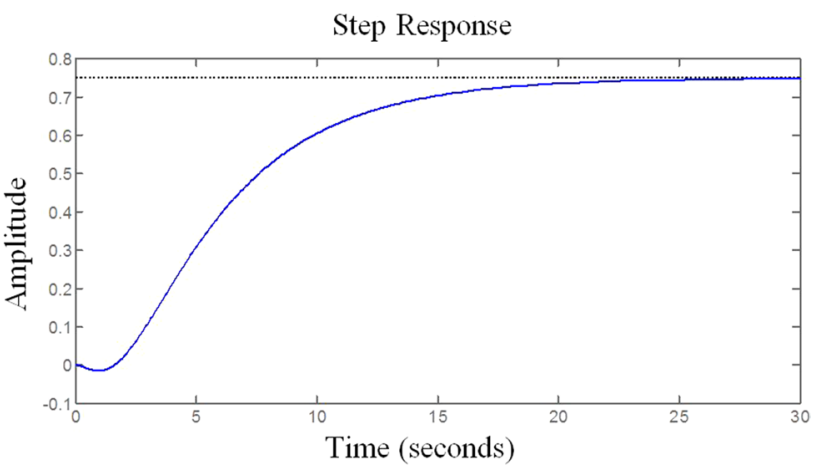

Fig. 8 Response (step) of the uncontrolled system

Table 6 Obtain parameters without controller

\begin{tabular}{ll}
\hline Parameters & Values \\
\hline Rise time & $10.2 \mathrm{~s}$ \\
Overshoot (\%) & 0 \\
Settling time & $19.8 \mathrm{~s}$ \\
\hline
\end{tabular}

performance. The optimized value of these gain parameters are shown in Table 9.

\section{Simulation and analysis}

The simulation of the proposed GA optimized PID controller is accomplished in MATLAB. The step response of the system is observed under various conditions such as with/ without PID controller. Also, the obtained results using different methods are compared among themselves. Here the step response means the output of the system for a step input. The step input indicates the input temperature. The output is also in temperature.

\subsection{Step response of conventional controller}

Here Fig. 8 shows the step response of the uncontrolled system. It is apparent from the response that, it is not competent. The rise time and setting time is too high. Besides, it has a large offset error which is difference between the reference input and output. Here the reference is step input that is one and the output is approximately 0.75 . Table 6 presents the values of settling time, rise time and percentage of overshoot that are found for the uncontrolled system.

Figure 9 shows the response of the system that is tuned by different methods of [7]. And Table 7 represents the characteristics parameters of the respective response. Here, the ZN method has the largest percentage of overshoot. On the other hand, the Nelder-Mead method and direct synthesis have least amount of overshoot. Though 


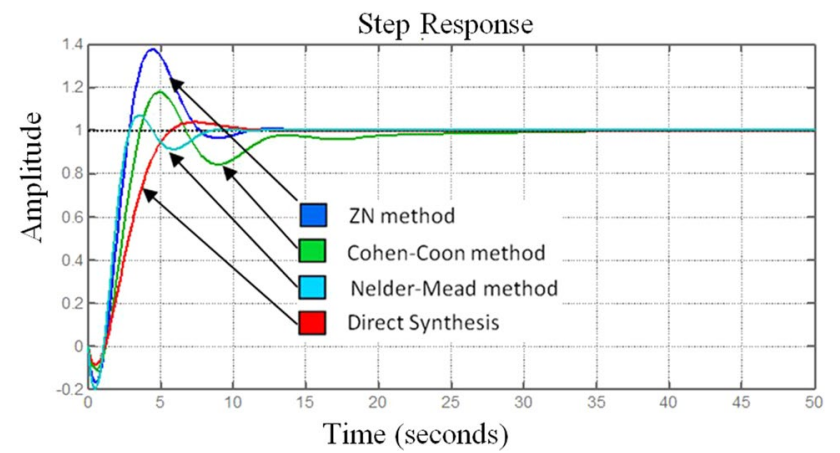

The response of the electric furnace with proposed GA-PID controller is shown in Fig. 10. Here, the performance of the proposed method is evaluated based on the percentage of overshoot, settling time, and rise time. From Fig. 10 it is found that transient response (settling time and rise time) is significantly improved and the settling time, percentage of overshoot, and rise time have the least value compared to the methods mentioned in [7] and steady-state error is nil. The values of these characteristics parameters of the proposed method are shown in Table 10.

Fig. 9 Response (step) of the system with conventional PID controller

Table 7 Characteristics parameters of different methods method

Table 8 Dependance of the charateristics parameters on the gain parameters

\begin{tabular}{lclll}
\hline Parameters & ZN method [7] & $\begin{array}{l}\text { Cohen-Coon } \\
\text { method [7] }\end{array}$ & $\begin{array}{l}\text { Direct synthesis } \\
\text { method [7] }\end{array}$ & $\begin{array}{l}\text { Nelder- } \\
\text { Mead } \\
\text { method [7] }\end{array}$ \\
\hline Rise time (s) & 1.2927 & 1.8049 & 3.0855 & 1.31 \\
Overshoot (\%) & 37.3952 & 17.5964 & 3.6878 & 7.0007 \\
Settling time (s) & 9.9689 & 20.8248 & 9.211 & 7.65 \\
\hline
\end{tabular}

\begin{tabular}{lllll}
\hline $\begin{array}{l}\text { Increasing the } \\
\text { parameter }\end{array}$ & Rise time & Overshoot & Settling time & Steady state error \\
\hline $\mathrm{K}_{\mathrm{p}}$ & Decreases & Increases & Small change & Decreases \\
$\mathrm{K}_{\mathrm{i}}$ & Decreases & Increases & Increases & Highly reduced \\
$\mathrm{K}_{\mathrm{d}}$ & Small change & Decreases & Decreases & Small change \\
\hline
\end{tabular}

direct synthesis has a minimum amount of overshoot, its rise and settling time is the largest. Comparing the above mention methods Nelder-Mead method shows a better result than the other methods. But its percentage of overshoot is greater than the direct synthesis method. Our proposed GA based PID controller reduces the above limitations which is presented in the next section.

\subsection{Step response of the proposed GA-PID controller}

As the characteristics of the step response mainly depend on the value of the gain parameters, these values should be selected carefully. The dependence of the characteristics parameters on the gain parameters are shown in Table 8 [18]. In order that all the characteristics parameters are in acceptable range, one needs to use the optimum value of the gain parameters $\left(\mathrm{K}_{\mathrm{p}}, \mathrm{K}_{\mathrm{i}}, \mathrm{K}_{\mathrm{d}}\right)$. After applying the genetic algorithm, the obtained optimized value of the gain parameters are shown in Table 9.
Table 9 Optimized value of $\mathrm{K}_{\mathrm{p}^{\prime}}$ $\mathrm{K}_{\mathrm{i}}$ and $\mathrm{K}_{\mathrm{d}}$

\begin{tabular}{ll}
\hline Parameters & Optimized values \\
\hline $\mathrm{K}_{\mathrm{p}}$ & 3.4066 \\
$\mathrm{~K}_{\mathrm{i}}$ & 0.6221 \\
$\mathrm{~K}_{\mathrm{d}}$ & 6.7512 \\
\hline
\end{tabular}

\section{SN Applied Sciences}

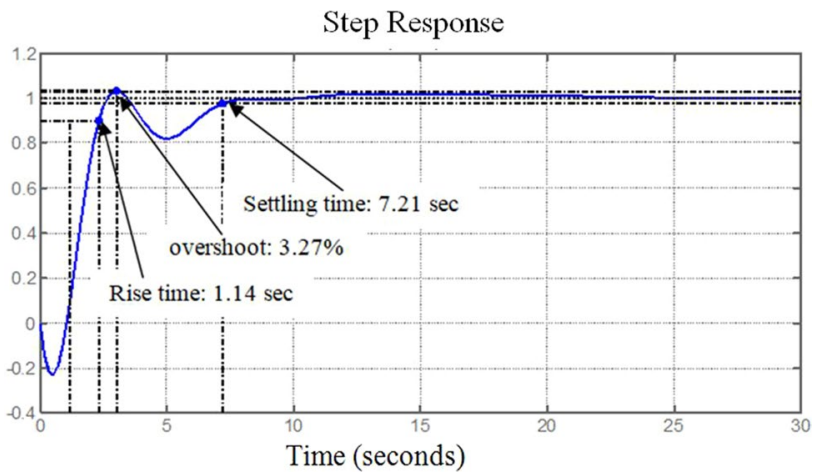

Fig. 10 Response of the system (GA-PID controller) 
Table 10 Obtain parameters with proposed method

\begin{tabular}{ll}
\hline Parameters & Values \\
\hline Rise time (s) & 1.14 \\
Overshoot (\%) & 3.27 \\
Settling time (s) & 7.21 \\
\hline
\end{tabular}

Table 11 Comparison of different methods

\begin{tabular}{lllll}
\hline Parameters & $\begin{array}{l}\text { Cohen- } \\
\text { Coon } \\
\text { method [7] }\end{array}$ & $\begin{array}{l}\text { Direct } \\
\text { synthesis } \\
\text { method [7] }\end{array}$ & $\begin{array}{l}\text { Nelder- } \\
\text { Mead } \\
\text { method [7] }\end{array}$ & $\begin{array}{l}\text { Pro- } \\
\text { posed } \\
\text { method }\end{array}$ \\
\hline $\begin{array}{l}\text { Rise time (s) } \\
\begin{array}{l}\text { Overshoot } \\
\text { (\%) }\end{array}\end{array}$ & 1.8049 & 3.0855 & 1.31 & 1.14 \\
$\begin{array}{l}\text { Settling time } \\
(\mathrm{s})\end{array}$ & 20.8248 & 3.6878 & 7.0007 & 3.27 \\
\hline
\end{tabular}

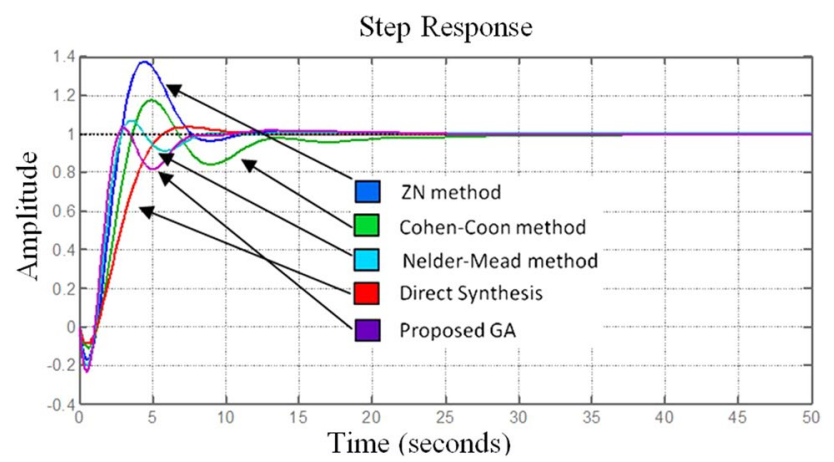

Fig. 11 Step response of the system in different methods

\subsection{Performance comparison}

Here Table 11 shows the comparative analysis of the proposed method with other methods such as CohenCoon method, Direct synthesis method, Nelder Mead method that are shown in [7]. The performance of the PID controller is appraised based on settling time, percentage of overshoot, and rise time. From the Table 11, it is apparent that the proposed method has minimum rise time $1.14 \mathrm{~s}$, settling time $7.21 \mathrm{~s}$ and percentage of overshoot $3.27 \%$ i.e. the proposed GA-PID controller shows more refined performance than other methods (Fig. 11).

Figure 12 represents the values of the gain parameters $\left(\mathrm{K}_{\mathrm{p}}, \mathrm{K}_{\mathrm{i}}, \mathrm{K}_{\mathrm{d}}\right)$ that are used in different methods of [7].

From the above simulation and data, it is apparent that the proposed genetic algorithm based optimization technique exhibits better performance than other methods.

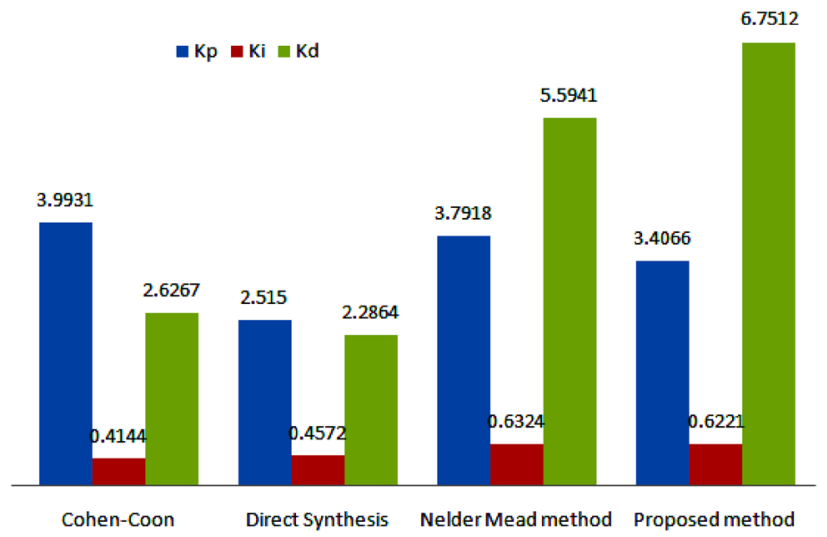

Fig. 12 Response of the system with proposed GA-PID controller

\section{Conclusion and future scope}

This research proposed an IAE based genetically optimized PID controller to control the temperature of the electric furnace. The IAE is considered as the object function for the optimization of error. From this optimization we acquire the optimum value of $\mathrm{K}_{\mathrm{p}}=3.4066, \mathrm{~K}_{\mathrm{i}}=0.6221$, and $K_{d}=6.7512$. For these values of the gain parameters, the step response of the system exhibits better result than conventional methods. Besides using the Routh-Hurwitz criterion for stability it is found that the system is stable. This sharp and prompt control over the temperature has a great impact on the food and medicine industries. As the temperature could be controlled precisely and instantly, we can avoid the change/degradation of the physical properties of the materials that are under process. Due to the long term operation of a process, its parameters may change with time. This will affect the precision as well as fast response in transient period. This needs further investigation to overcome the above limitation.

\section{Compliance with ethical standards}

Conflict of interest The authors declare they have no conflict of interest.

\section{References}

1. Li J, Yan C, Liu J (2012) Design of temperature control system based on fuzzy PID, advanced materials research, vol 418-420. Trans Tech Publications, Switzerland, pp 1756-1759

2. Jayachitra A, Vinodha R (2014) Genetic algorithm based PID controller tuning approach for continuous stirred tank reactor, Hindawi Publishing Corporation. Adv Artif Intell 2014, 791230

3. Sabura Banu U, Uma G (2007) ANFIS gain scheduled CSTR with genetic algorithm based PID minimizing integral square error, 
In: IET-UK international conference on information and communication technology in electrical sciences (ICTES 2007), Dr. M.G.R. University, Chennai, Tamil Nadu, India. Dec. 20-22, pp 57-62

4. Rahmat MF, Yazdani AM, Movahed MA, Mahmoudzadeh S (2011) Temperature control of a continuous stirred tank reactor by means of two different intelligent strategies. Int J Smart Sens Intell Syst 4(2):244-267

5. Chunchen W, Feng C, Guang Z, Ming Y, Liangzhe L, Taihu W (2017) Design of genetic algorithm optimized PID controller for gas mixture system. In: 2017 IEEE 13th international conference on electronic measurement \& instruments, 13th IEEE international conference on electronic measurement \& instruments (ICEMI), 20-22 Oct. 2017, pp 6-9

6. Ayam M, Liqaa SM, Raoof TH (2016) Speed control for separately excited DC motor with PID controller, GA, And PSO. Int J Recent Sci Res 7(7):12673-12678

7. Sinlapakun V, Assawinchaichote W (2015) Optimized PID controller design for electric furnace temperature systems with Nelder Mead Algorithm. In: 12th international conference on electrical engineering/electronics, computer, telecommunications and information technology (ECTI-CON), 24-27 June 2015, pp 1-4

8. Jiang W, Jiang $X$ (2012) Design of an intelligent temperature control system based on the fuzzy self-tuning PID. In: International symposium on safety science and engineering in China, 2012 (ISSSE-2012), Procedia Engineering 43, pp 307-311

9. Flores-Morán E, Yánez-Pazmiño W, Barzola-Monteses J (2018) Genetic algorithm and fuzzy self-tuning PID for DC motor position controllers. In: 2018 19th international carpathian control conference (ICCC), Szilvasvarad, pp 162-168

10. Deng C, Wang Z (2018) Self-learning fuzzy algorithm optimized temperature control and efficiency monitoring of heat exchanger. In: 2018 37th Chinese control conference (CCC), Wuhan, pp 3394-3399

11. Valarmathi $R$, Theerthagiri $P R$, Rakeshkumar S, Gomathi V (2018) Design of genetic algorithm based internal model controller for a heat exchanger. In: 2018 international conference on computation of power, energy, information and communication (ICCPEIC), Chennai, pp 489-495

12. Han Y, Jinling J, Guangjian C, Xizhen C (2011) Temperature control of electric furnace based on fuzzy PID. In: International conference on electronics and optoelectronics (ICEOE 201 1), 2011, Proceedings of 2011 international conference on electronics and optoelectronics, pp 41-44

13. Vahedpour M, Ranjbar Noei A, Agheh Kholerdi H (2015) Comparison between performance of conventional, fuzzy and fractional order PID controllers in practical speed control of induction motors. In: 2nd international conference on knowledge-base engineering and innovation (KBEI) November 5-6, pp 912-916

14. Jaen-Cuellar AY, de Romero-Troncoso RJ, Morales-Velazquez L, Osornio-Rios RA (2013) PID-controller tuning optimization with genetic algorithms in servo systems. Int J Adv Robot Syst 11:324

15. Elsrogy WM, Fkirin MA, Moustafa Hassan MA (2013) Speed control of DC motor using PID controller based on artificial intelligence techniques. In: International conference on control, decision and information technologies (CoDIT), pp 196-201

16. Meena DC, Devanshu A (2017) Genetic algorithm tuned PID controller for process control. In: International conference on inventive systems and control, international conference on inventive systems and control (ICISC), pp 1-6

17. Mustafa Kamal Md, Mathew L, Chatterji S (2014) Speed control of brushless DC motor using intelligent controllers. In: Students conference on engineering and systems. pp 1-5

18. Sharma K, Palwalia DK (2017) A modified PID control with adaptive fuzzy controller applied to DC motor. In: Proceedings of the international conference on information, communication, instrumentation and control (ICICIC), Indore, India, 17-19 Aug. 2017, pp 1-6

Publisher's Note Springer Nature remains neutral with regard to jurisdictional claims in published maps and institutional affiliations. 